\title{
The effect of macro polymer fibres length and content on the fibre reinforced concrete
}

\author{
Aleksandra Mariak $^{1, *}$, and Marzena Kurpińska $^{1}$ \\ ${ }^{1}$ Gdańsk University of Technology, Faculty of Civil and Environmental Engineering, \\ Narutowicza 11/12, 80-233 Gdańsk, Poland
}

\begin{abstract}
The paper presents studies of a ready-mix concrete containing polymer fibres of three different lengths: 24,38 and $54 \mathrm{~mm}$. The performed tests allowed to determine the effect of fibre volume fraction and length on the concrete strength. The basic parameters of concrete mixture (consistency, air content and bulk density) were identified. Fibre reinforced concrete belongs to a group of composite materials. The polymer fibres are applied in the concrete in structures where the reduction of shrinkage cracking as well as corrosion resistance and fire temperatures are required. It is widely known, that the cracking behaviour of concrete structures depends on flexural tensile strength of concrete. The addition of fibres significantly improves the tensile strength. The experimental study, including axial compressive strength and center-point loading flexural tensile strength, was carried out. The scope of the research was also expanded by the usage of a scanning microscope. The test results showed the effect of fibre length and fibre combinations on mechanical properties of concrete. The effect of the research is to formulate guidelines due to the quantity of macro polymer fibres. In general, appropriate fibre content brings a beneficial effect e.g. improves better workability of a concrete mixture.
\end{abstract}

\section{Introduction}

Fibre reinforced concrete is composite material with cement matrix and short-cut, dispersed steel, glass, carbon or plastic fibres [1]. It differs from ordinary concrete with a change of plastic behaviour, thus it is a very interesting material of multiple applications. It is commonly used for industrial floors. However, for the production of typical concrete elements steel reinforcement bars are more and more often being replaced by dispersed reinforcement. Additional protection of the reinforced concrete surface by impregnation can significantly reduce the process of gas and liquid permeability. Modification of physical and mechanical properties of concrete makes the structure more resistant to abrasion, erosion and corrosion [2-4] and shows an economical reason too [5-6].

\footnotetext{
*Corresponding author: aleksandra.mariak@pg.edu.pl
} 


\section{Fibres characteristics}

The matrix of fibre reinforced concrete is a brittle material, but limit deformability of dispersed fibres is significantly higher than the deformability of the matrix. As compared to high-strength composites, the percentage of dispersed fibre reinforcement is approximately $1-2 \%$ by volume. Even just a small portion of fibres brings a significant modification of concrete properties. Bulk density of cement grout ranges between $2,0-2,25 \mathrm{~g} / \mathrm{cm}^{3}$, Young's modulus is $10-30 \mathrm{GPa}$ and tensile strength $3-6 \mathrm{MPa}$. The addition of fibres significantly changes its performance according to the characteristics of the fibre type used (Table 1). Fibres can be dosed in different configurations and intermediate solutions can be created in the form of MFRP, GFRP, GFRC, MFRC fibres (Fig. 1).

Table 1. Properties of fibres [7].

\begin{tabular}{|l|c|c|c|c|c|}
\hline Fibre type & $\begin{array}{c}\phi \\
{[\mu \mathrm{m}]}\end{array}$ & $\begin{array}{c}\rho \\
{\left[\mathrm{g} / \mathrm{cm}^{3}\right]}\end{array}$ & $\begin{array}{c}E \\
{[\mathrm{GPa}]}\end{array}$ & $\begin{array}{c}f_{c t m} \\
{[\mathrm{MPa}]}\end{array}$ & $\begin{array}{c}V \\
{[\%]}\end{array}$ \\
\hline steel & $5-500$ & 7,84 & 200 & $500-2000$ & $0,5-3,5$ \\
\hline glass & $9-15$ & 2,60 & $70-80$ & $2000-4000$ & $2-3,5$ \\
\hline asbestos & $0,02-04$ & 3,00 & 180 & 3300 & $2-3$ \\
\hline polypropylene & $20-200$ & 0,90 & $5-7$ & $500-750$ & 8 \\
\hline nylon & - & 1,10 & 4 & 900 & $13-15$ \\
\hline polyethylene & - & 0,95 & 0,30 & 0,7 & 10 \\
\hline carbon & 9 & 1,90 & 230 & 260 & 1 \\
\hline kevlar & 10 & 1,45 & $65-133$ & 360 & $2-4$ \\
\hline acrylic & 18 & 1,18 & $14-19,5$ & $400-1000$ & 3 \\
\hline
\end{tabular}

The question of the choice of the appropriate type and amount of fibres and their influence on mechanical properties is the subject of a multiple scientific research [8-14]. Many research results have been published on fibre reinforced concrete, but a large number of issues have not been investigated yet. Much more research work has been published on steel fibre concrete than on polymer fibre concrete. It is well known that the introduction of high strength thin polymer fibres into the fragile matrix results in a new building material, not comparable to concrete or steel reinforced concrete. The presence of fibres modifies the properties of the surrounding matrix.

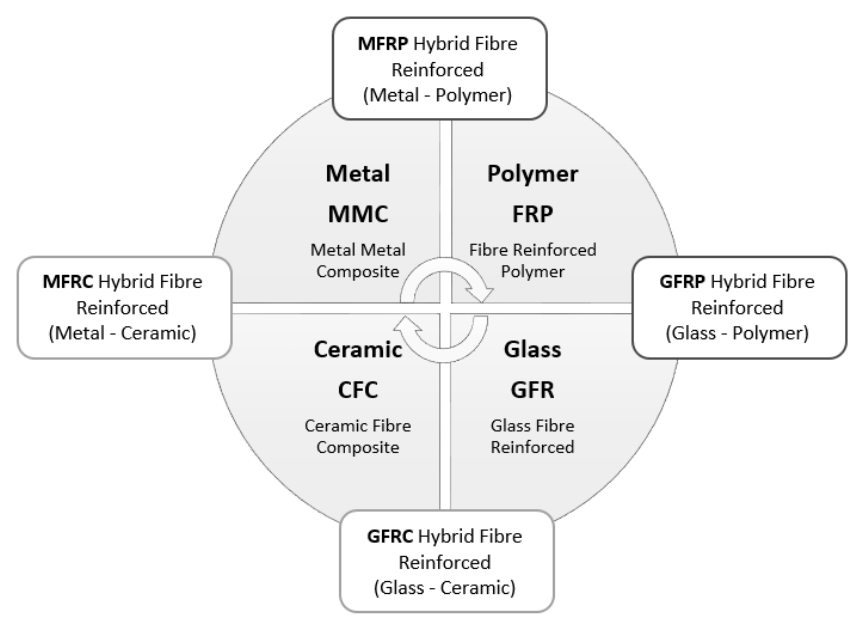

Fig. 1. Types of fibres used in concrete. 


\section{Macro polymer fibres}

In accordance with EN 14889-2, polymer fibres are classified as II class fibres - macrofibres with a diameter of $>0,30 \mathrm{~mm}$. They are usually used to increase so called residual flexural strength. They have structural applications and influence the load capacity of the elements, and thus their strength. Polymeric fibres inhibit crack propagation [15]. In this respect, observation of the material's behaviour in the post-cracking phase is particularly important. Such tests should only be carried out when the stress condition is as homogeneous as possible. Conventional strength tests known from concrete technology, such as compression or splitting tests, are not suitable because the actual stress distribution is not known. Relatively uniform state of deformation occurs in axial tensile test. One of the innovative methods of testing fibre reinforced concrete is X-Ray tomography [16]. Another way is to monitor concrete elements implemented in many objects by research teams [17-19].

The effectiveness of the added fibres depends e.g. on: fibres content, their shape, dimensions and adhesion to the cement matrix. The adhesion of the polymer fibre to the cement matrix has a significant impact on the mechanical properties of the composite, and in particular on the amount of energy accumulated during the destruction process (Fig. 2). During specimen destruction process, at the beginning of the elastic deformation range, longitudinal crack appears at a certain distance from the fibre surface.
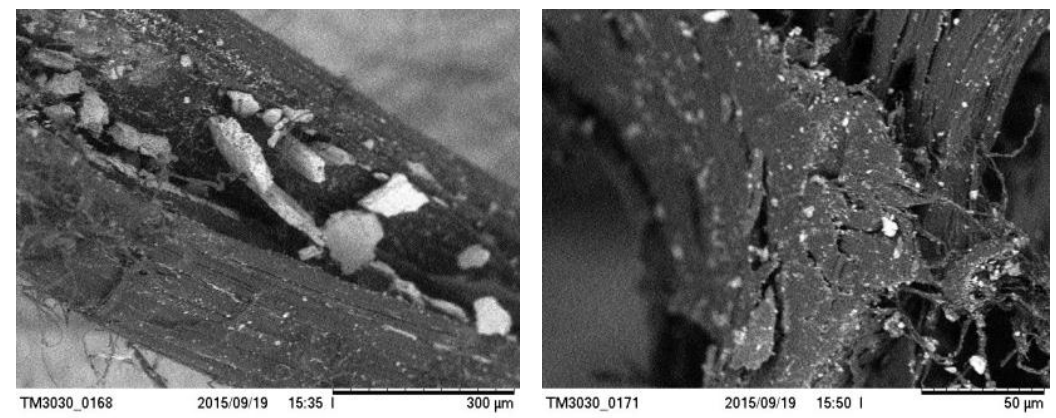

Fig. 2. Adhesion of Astra Polyex Mesh 2000 fibre to cement matrix. Photo SEM Hitachi TM3030.

However, not all phenomena occurring in the contact zone between grout and fibre are noticeable in the diagram of the pulling force as a function of displacement. It may be explained with local extinction of mutual displacements due to friction between fibre and matrix [13]. Improved adhesion enhances fibre resistance to pulling force.

Based on scientific research, many empirical formulae describing the influence of factors on the mechanical properties of fibre reinforced concrete are derived. High flexural tensile strength and high flexural cracking resistance are the basic characteristics of concrete with fibres added. With low fibres content, the flexural tensile strength does not change as rapidly as in case of non-reinforced concrete. After exceeding the limit of proportional deformation, the behaviour of concrete changes suddenly, both before and after exceeding the destructive load. The specimen does not break and exhibits a significant continuous resistance while further deformed. At the same time, the nature of destruction varies depending on the type and amount of fibre used. Cracking resistance refers to the ability of fibre reinforced concrete to absorb loads in a defined deformation range. It is a measure of stress changes in concrete during cracking.

Numerous studies are being carried out in scientific centres around the world to determine the relationship between the adhesion characteristics of the matrix to polymer fibres of different shapes and the mechanical properties of fibre reinforced concrete. 
Unfortunately, most of the publications concern fibre reinforced concretes containing steel fibre $[9,20]$ while much less scientific research is devoted to cement composites modified with polymer, basalt, glass or kevlar fibres.

\section{Experimental studies}

The main aim of the study was to determine the effect of polymer fibre volume fraction and length on the improvements of mechanical concrete properties. Experimental studies were conducted using copolymer fibres (polypropylene ethylene) Astra Polyex Mesh 2000. The considered fibres are filament fibres twisted into bundles and available in three lengths 24 , 38 and $54 \mathrm{~mm}$ (Fig. 3). Fibres parameters were given in Table 2. The paper presents the results of preliminary studies aimed at determining the influence of fibre length on the change of concrete properties. The tests were carried out on concrete mixture, modified with fifteen compositions of different fibre lengths. A fixed total fibre mass of $4 \mathrm{~kg} / \mathrm{m}^{3}$ has been adopted. Individual compositions were marked with the following symbols MFLC I MFLC XV.

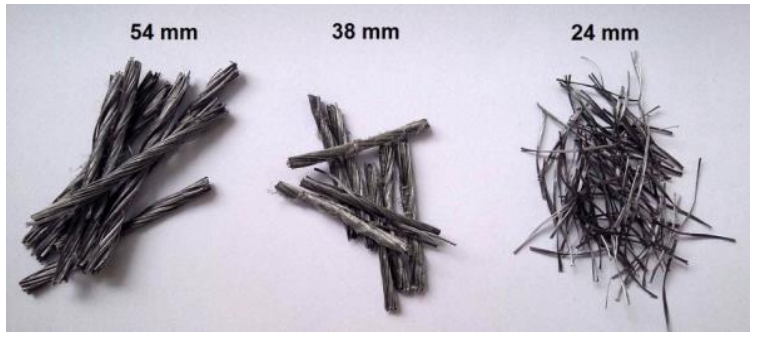

Fig. 3. ASTRA PolyexMesh 2000 fibres in lengths of 54, 38, $24 \mathrm{~mm}$.

In all tests, the same composition of concrete matrix class C $30 / 37$ was used: CEM I $42,5 \mathrm{R}-380 \mathrm{~kg}$, water $-196 \mathrm{~kg}$, sand $0 / 2-760 \mathrm{~kg}$, gravel $2 / 8-1050 \mathrm{~kg}$, PCE superplasticizer $-0,65 \%$ of cement mass, Astra Polyex Mesh 2000 fibres $-4 \mathrm{~kg}$, w/c = 0,52.

Table 2. Parameters of Astra Polyex Mesh 2000 polymer fibres.

\begin{tabular}{|l|c|c|c|}
\hline length [mm] & 54 & 38 & 24 \\
\hline fibre diameter [mm] & \multicolumn{3}{|c|}{0,45} \\
\hline tensile strength [MPa] & \multicolumn{3}{|c|}{$650-750$} \\
\hline slenderness $1 / \mathrm{d}[-]$ & 120 & 84 & 63 \\
\hline number of fibres per $1 \mathrm{~kg}[\mathrm{pcs}]$. & 11000 & 156000 & 250000 \\
\hline total length of reinforcement [mb/kg] & 5940 & 5928 & 13500 \\
\hline recommended dose $\left[\mathrm{kg} / \mathrm{m}^{3}\right]$ & \multicolumn{3}{|c|}{$1,5-5$} \\
\hline Young modulus E of a fibre $[\mathrm{GPa}]$ & \multicolumn{3}{|c|}{5,9} \\
\hline
\end{tabular}

The choice of the content and type of dosed fibres can be presented graphically using a triangle Fig. 4. The sides of the triangle are the shares of the individual fibre lengths: 24 , 38 and $54 \mathrm{~mm}$ and their percentage content: $0 \%, 25 \%, 50 \%, 75 \%, 100 \%$. The composition of fifteen different concrete mixtures is characterised by a varying combination of different length fibre content. The table of quantities of the selected fibre for each tested mixture is presented in Table 3. 


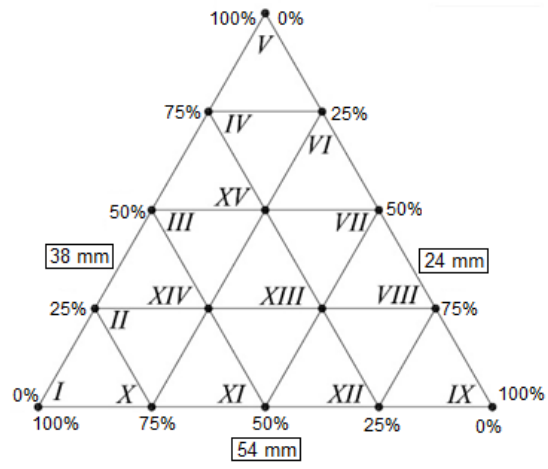

Fig. 4. Triangle of fibre lengths selection.

Table 3. Percentage content of fibres for every mixture.

\begin{tabular}{|c|c|c|c|}
\hline \multirow{2}{*}{$\begin{array}{c}\text { Mixture no. } \\
\text { MFLC }\end{array}$} & \multicolumn{3}{|c|}{ Percentage content of fibres [\%] } \\
\cline { 2 - 4 } & $\mathbf{5 4} \mathbf{~ m m}$ & $\mathbf{3 8} \mathbf{~ m m}$ & $\mathbf{2 4} \mathbf{~ m m}$ \\
\hline I & 100 & 0 & 0 \\
\hline II & 75 & 25 & 0 \\
\hline III & 50 & 50 & 0 \\
\hline IV & 25 & 75 & 0 \\
\hline V & 0 & 100 & 0 \\
\hline VI & 0 & 75 & 25 \\
\hline VII & 0 & 50 & 50 \\
\hline VIII & 0 & 25 & 75 \\
\hline IX & 0 & 0 & 100 \\
\hline X & 75 & 0 & 25 \\
\hline XI & 50 & 0 & 50 \\
\hline XII & 25 & 0 & 75 \\
\hline XIII & 25 & 25 & 50 \\
\hline XIV & 50 & 25 & 25 \\
\hline XV & 25 & 50 & 25 \\
\hline
\end{tabular}

Prism specimens of the dimensions of $40 \times 40 \times 160 \mathrm{~mm}$ were prepared from these concrete mixtures in the quantity of 9 pcs. for each variant as well as $100 \mathrm{~mm}$ cubic samples were prepared from these concrete mixtures in the quantity $12 \mathrm{pcs}$. for each variant. The specimens were compacted using a vibrating table, with the same vibration times for a specific series of specimens. Before the specimens were produced, the consistency and air content in the concrete mixture were examined.

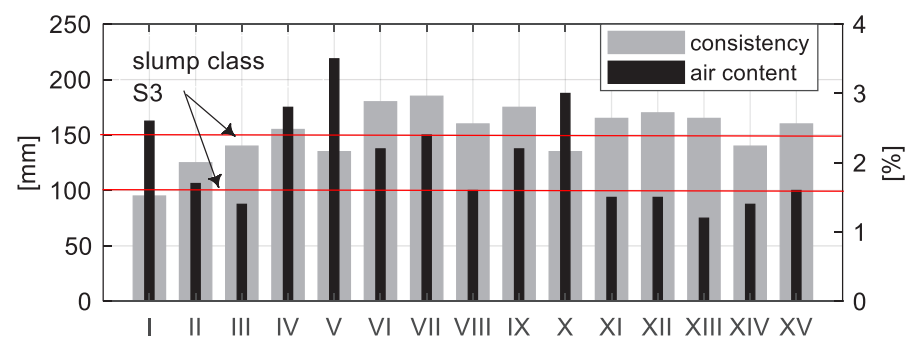

Fig. 5. The consistency and air content of mixtures. 
The consistency measurement results were presented in Fig. 5, measured using Abrams cone's slump after 45 minutes from mixing cement with water. Fifteen mixtures with a total volume of $35 \mathrm{dm}^{3}$ were made. It was assumed that after $45 \mathrm{~min}$ the consistency of concrete mixture should reach class S3 $(100 \div 150 \mathrm{~mm})$. The first acceptance criterion was a visual evaluation of the concrete mixture. Mixture should not separate and there should be no bleeding. During the study it was observed that concrete mixtures marked with the symbols MFLC II, III, V, X and XIV (consistency 125 - $140 \mathrm{~mm}$ ) featured a very good workability. Consistency of mixtures of MFLC IV, VI, VII, VIII, IX, XI, XII, XIII and XV where higher than $150 \mathrm{~mm}$. Bleeding symptoms were noticed in mixtures marked with MFLC VI and VII. Air content of the concrete mixtures ranged from $1,2 \%$ to $3,5 \%$, with the highest air content in mixtures marked MFLC V, X, IV and I. Bulk density of all mixtures ranged from 2306 to $2368 \mathrm{~kg} / \mathrm{m}^{3}$.

The prepared specimens were cured in water at a temperature of $20 \pm 2{ }^{\circ} \mathrm{C}$ for 28 days (for beams) and 90 days (for cubes). Then, strength tests were carried out on predetermined dates. Beams $(40 \times 40 \times 40 \times 160 \mathrm{~mm})$ were subjected to the flexural tensile strength test (Fig. 6), and then compressive strength test were carried out on half-beams aged 1, 7 and 28 days. In the case of flexural tensile strength test for all specimens the increase in tensile strength was recorded after 28 days in relation to the 7-day tensile strength (Fig. 7). The largest increase concerned specimens made from mixtures MFLC VII, VIII and IX. These mixtures did not contain $54 \mathrm{~mm}$ fibres but mainly had short fibres. The standard deviation for tensile strength for each set of samples in specified term did not exceed the following values: SD1 $<0,33$, SD7 $<0,54$, SD28 $<0,78[\mathrm{MPa}]$. Based on the obtained results it can be concluded that the strength of the cement matrix is very important. Whereas fibre content specified by the manufacturer is between $1,5 \mathrm{~kg}$ and $5 \mathrm{~kg}$, tests indicate that the recommended fibre content shall not be greater than $3 \mathrm{~kg}$. The type and size of specimens tested are also of key significance. The aim of the study was to verify the influence of fibre content on the rheological changes of concrete mixtures and on the mechanical properties of concrete. Noticeable changes of strength indicate that it would be recommended to produce specimens in accordance with PN-EN 14889-2 for all variants.
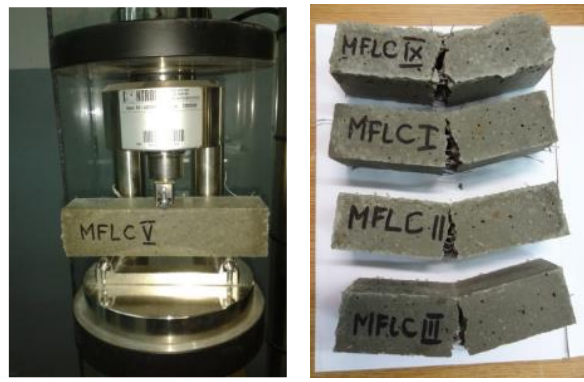

Fig. 6. Flexural tensile strength test.

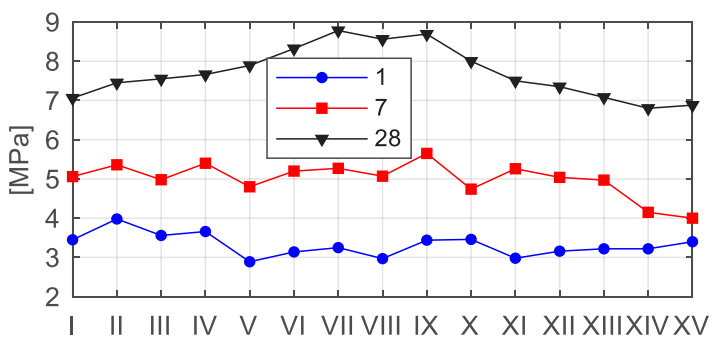

Fig. 7. Prism tensile strength after 1, 7, 28 days. 
The results of compression strength tests carried out on half-beams were presented in Fig. 8a. The highest strength after 28 days was noted in case of MFLC VI (57,7 MPa), IV (56,2 MPa), VII $(55,7 \mathrm{MPa}), X I I(54,3 \mathrm{MPa})$ and X $(54,2 \mathrm{MPa})$. In all cases the compressive strength after 28 days was higher than $50 \mathrm{MPa}$. After 1 day of hardening, the highest compressive strength was obtained in case of MFLC IX (19,3 MPa) and $\mathrm{X}(18,8 \mathrm{MPa})$ compositions, while the lowest strength was obtained in case of MFLC XIV (13,6 MPa) and XV (13,9 MPa) compositions. The standard deviation for prism compressive strength for each set of samples in specified term did not exceed the following values: SD1 <1,55, SD7 < 4,20, SD28 <3,13 [MPa].

In order to determine the scale effect, compression strength tests were also carried out on $100 \mathrm{~mm}$ cubic specimens. For each grout, 6 specimens aged 28 and 90 days were tested. The results of compressive strength tests for cubic specimens after 28 and 90 days of curing are characterized by low variability (Fig. 8b). Only three mixtures show a decrease in long-term strength (MFLC II, V, VII). After 28 days, the highest compressive strength was obtained for mixtures marked MFLC VII (50,4 MPa), XI (50,0 MPa), VI (49,5 MPa) and XIV (49,4 MPa), while the lowest one for MFLC XIII (41,2 MPa). The standard deviation for prism compressive strength for each set of samples in specified term did not exceed the following values: SD28 $<2,54$, SD90 $<4,63[\mathrm{MPa}]$.
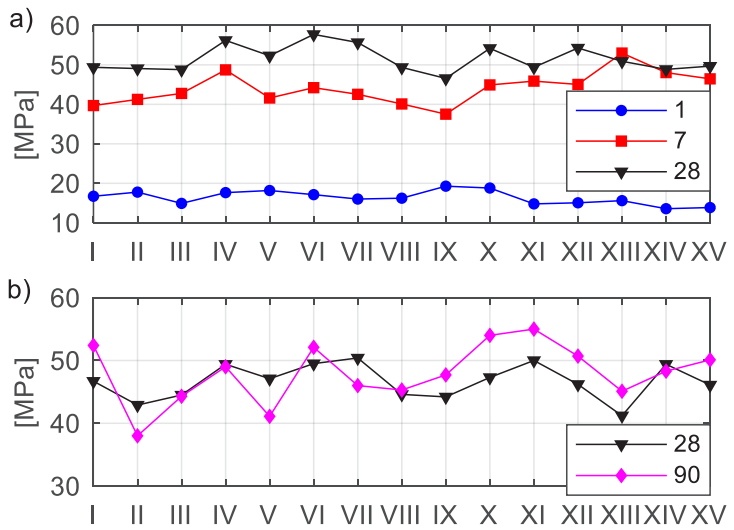

Fig. 8. a) Prism compressive strength, b) Compressive strength of $100 \mathrm{~mm}$ cube.

\section{Conclusions}

Based on the conducted experimental studies, the following conclusions were formulated:

- All mixtures featured good workability, with the best workability and rheology was noted in case of fibre reinforced concrete mixtures marked with MFLC VI, VII (mixture of $38 \mathrm{~mm}$ and $24 \mathrm{~mm}$ fibres) and IV (mix of $54 \mathrm{~mm}$ and $38 \mathrm{~mm}$ fibres). While using the mixture containing $100 \%$ of $54 \mathrm{~mm}$ long fibres, the concrete mixture revealed slight bleeding. The recipe needs correction and application for example some addition of zeolite. This additive improves the workability of the concrete mixture and completely eliminates disadvantageous bleeding. It causes strength parameters increase, as it was confirmed by numerous tests.

- The results of the compression strength test after 28 days determined on specimens $40 \times 40 \times 160 \mathrm{~mm}$ are approximately $15 \%$ - $20 \%$ higher than those obtained on cubic samples with a side of $100 \mathrm{~mm}$.

- In the case of the flexural tensile strength test, tensile strength results obtained after 28 days are approximately $10 \%-30 \%$ higher than results obtained after 7 days. 
- The test results are influenced by the specimen size, especially if more than $2 \mathrm{~kg}$ of fibres were used and the fibre length exceeds $24 \mathrm{~mm}$.

- Authors noted that the amount of cement grout should be adjusted so as to good use the adhesive properties of polymer fibres to the cement matrix and thus increase the cohesion of the concrete composite. Some mixtures show a decrease in long-term strength (after 90 days) which may be the result of less fibre adhesion and dispersion.

- Contact surface of polymer fibres to the cement matrix should be taken into account at the phase of designing the fibre reinforced concrete mixture. For this purpose it is possible to modify the cement matrix with selected admixtures and additives.

\section{References}

1. A. M. Neville, Properties of Concrete, fourth edition, London, (1996)

2. M. Kurpińska, T. Ferenc, II International Conference of Computational Methods in Engineering Science, (2017)

3. M. Kurpińska, T. Ferenc, Shell Structures: Theory and Applications, 4, 549-552 (2018)

4. N. Ciak, M. Ciak, J. Harasymiuk, IX Konferencja Dni Betonu, 2, 499-511, (2016)

5. B. Grzyl, E. Miszewska-Urbańska, M. Apollo, E3S Web of Conferences, EDP Sciences, (2017)

6. D. Kowalski, B. Grzyl, A. Kristowski, Civil and Environmental Engineering Reports 26.3, 5-13 (2017)

7. A. Gallowicz-Sarzalejo, Fibres as structural element for reinforcement of concrete, Technical Manualy, Maccaferri, (2015)

8. M. A. Glinicki, A. Wysokowski, A. Żurawicka, Mechanical properties of fibreced concrete for thin repairs concrete pavements. Brittle Matrix Composities VII, 75-84 (2005)

9. J. P. Romualdi, J. A. Mandel, J. Amer. Concr. Inst., 61, 657-670 (1964)

10. A. Bentur, S. Mindes, Fibre reinforced cementious composities, Elsevier Applied Science, London and New York, (1990)

11. A. M. Brandt, Cement based composities: materials, mechanical and properties and performance, E\&FN SPON, London, (1995)

12. A. Katz, A. Bentur, Advanced Cement Based Materials, 3, 1-13 (1996)

13. A. M. Brandt, M. A. Glinicki, Archives of Civil Engineering, 3, 399-426 (1999)

14. J. Kasperkiewicz, Konferencja Naukowa - Jabłonna 1979, Wrocław, (1982)

15. F. Grzymski, Builder, 90, 90-93 (2017)

16. Ł. Skarżyński, J. Tejchman, Strain, 52 (1), 26-45 (2016)

17. J. Chróścielewski, A. Mariak, A. Sabik, B. Meronk, K. Wilde, Adv. Sci. Technol. Res. J., 10, 254-262 (2016)

18. M. Miśkiewicz, Ł. Pyrzowski, K. Wilde, O. Mitrosz, Polish Maritime Research, 24, 149-155 (2017)

19. A. Mariak, J. Chróścielewski, K. Wilde, Shell Structures: Theory and Applications, 4, 557-560 (2018)

20. M. A. Glinicki, Drogi i Mosty, 3, 5-36 (2002) 